This is an electronic reprint of the original article. This reprint may differ from the original in pagination and typographic detail.

Author(s): Saajanaho, Milla; Rantakokko, Merja; Portegijs, Erja; Törmäkangas, Timo; Eronen, Johanna; Tsai, Li-Tang; Jylhä, Marja; Rantanen, Taina

Title: $\quad$ Personal goals and changes in life-space mobility among older people

Year: $\quad 2015$

Version:

Please cite the original version:

Saajanaho, M., Rantakokko, M., Portegijs, E., Törmäkangas, T., Eronen, J., Tsai, L.-T., Jylhä, M., \& Rantanen, T. (2015). Personal goals and changes in life-space mobility among older people. Preventive Medicine, 81, 163-167.

https://doi.org/10.1016/j.ypmed.2015.08.015

All material supplied via JYX is protected by copyright and other intellectual property rights, and duplication or sale of all or part of any of the repository collections is not permitted, except that material may be duplicated by you for your research use or educational purposes in electronic or print form. You must obtain permission for any other use. Electronic or print copies may not be offered, whether for sale or otherwise to anyone who is not an authorised user. 


\section{Personal goals and changes in life-space mobility among older people}

Milla Saajanaho MSc, Merja Rantakokko PhD, Erja Portegijs PhD, Timo Törmäkangas PhD, Johanna Eronen MSc, Li-Tang Tsai MSc, Marja Jylhä MD, PhD, Taina Rantanen PhD

\section{Author Note}

Milla Saajanaho, Merja Rantakokko, Erja Portegijs, Timo Törmäkangas, Johanna Eronen, Li-Tang Tsai and Taina Rantanen, Gerontology Research Center* and Department of Health Sciences, University of Jyvaskyla, FI-40014 Jyvaskyla, Finland; Marja Jylhä, Gerontology Research Center*, School of Health Sciences, University of Tampere, FI-33014 Tampere, Finland.

*Gerontology Research Center is a joint effort between the University of Jyvaskyla and the University of Tampere.

Corresponding concerning this article should be addressed to Milla Saajanaho, University of Jyvaskyla, Gerontology Research Center and the Department of Health Sciences, P.O. Box 35, FI-40014 University of Jyvaskyla, Finland, Phone +358 40833 4190, e-mail: milla.saajanaho@jyu.fi

Word count abstract: 230

Word count main text: 3221

Abbreviations: LISPE: Life-Space Mobility in Old Age; LSMC score: life-space mobility composite score; GEE model: generalized estimating equations model 


\title{
Personal goals and changes in life-space mobility among older people
}

\begin{abstract}
Life-space mobility - the spatial extent of mobility in daily life - is associated with quality of life and physical functioning, but may also be influenced by future orientation expressed in personal goals. The aim of this study was to explore how different personal goals predict changes in older people's life-space mobility. This prospective cohort study with a two-year follow-up included 824 community-dwelling people aged 75 to 90 years from the municipalities of Jyväskylä and Muurame in Central Finland. As part of the Life-Space Mobility in Old Age study (LISPE), which was conducted between 2012 and 2014, the participants responded to the Life-Space Assessment and Personal Project Analysis in addition to questions on socio-demographics and health. Data were analyzed using generalized estimation equation models. The results showed that goals indicating a desire to be active in daily life, to stay mentally alert, and to exercise were associated with higher lifespace mobility, and that the associations remained over the follow-up years. Goals related to maintaining functioning predicted higher life-space mobility at the two-year follow-up. In contrast, goals reflecting improvement of poor physical functioning predicted lower lifespace mobility. The results remained significant even when adjusted for indicators of health and functioning. This study indicates that supporting older people in striving for relevant personal goals in their lives might contribute to a larger life-space and thus also to improved quality of life in old age.
\end{abstract}

Keywords: life-space mobility, personal goals, aging, community participation 


\section{Introduction}

Going outside one's home and moving in and outside of the neighborhood is an important element in living a meaningful life in old age, as it enables the use of community amenities and participation in social activities [1]. Restrictions in life-space mobility, a measure reflecting everyday movement in different life-space areas (bedroom, home, outside home, neighborhood, town, outside town; [2]), is common in old age [3, 4]. Besides higher age, functional limitations have consistently been correlated with lower life-space mobility. Also, female sex, lower education and income, depressive symptoms, cognitive decline, and transportation problems are associated with life-space restriction [4-7]. Higher life-space mobility has been associated with sense of autonomy [8], extraverted personality, social activity, and orienting more toward the future instead of only the present day [4]. Higher lifespace mobility correlates with better quality of life $[9,10]$, and may even decrease the risk of frailty and mortality [11]. Consequently, finding ways to maintain or increase life-space mobility could contribute to well-being in old age.

People often act according to their personal goals [12], which are highly individualized states that people strive to achieve or avoid in the future [13]. In old age, personal goals most often relate to health, close relationships and leisure time activities [14, 15]. Previous research has indicated that older people's goals are affected by their health and functional limitations $[14,15]$. Previously, goal engagement in old age has been associated with more activity participation [16] and better psychological well-being [14]. Also, having relevant personal goals may help older people maintain higher exercise activity [17]. Goal engagement may be a resource for facing age-related health deterioration [18], and thus potentially prevent people from drifting into a vicious circle resulting in decreased life-space mobility and eventually home confinement - a situation that in practice renders active aging impossible.

Life-space mobility is affected by multiple factors, and not by physical functioning alone [3]. Previous studies have not explored how goal engagement is reflected in life-space mobility, although it seems reasonable to assume that some goals require moving in a larger life-space than others. Personal goals can function as a pathway to maintaining valued behaviors throughout the life course [19]. It can be argued that not striving for personal goals could constitute a risk factor for life-space restriction, whereas engagement in relevant personal goals could contribute to maintaining and achieving higher life-space mobility. The 
purpose of this study was to explore how the content of older people's personal goals affects life-space mobility over a two-year follow-up.

\section{Methods}

Participants

The present data came from the Life-Space Mobility in Old Age study (LISPE), which was a two-year prospective cohort study of community-dwelling older people aged 75 to 90 conducted in the municipalities of Jyväskylä and Muurame in Central Finland. Details of the recruitment procedure and the study flow of LISPE have been described in detail elsewhere [20]. A random sample of 2550 people was drawn from the national population register. These individuals were contacted to ascertain their interest in taking part in the study. To be included, the participants had to be living independently in their own homes, not have any severe problems in communication, and be willing to participate in the study. Finally, 848 people (62\% female) participated in a structured home-interview implemented between January and June in 2012. The first follow-up was conducted one year, and the second follow-up two years after the baseline assessment. The first follow-up was conducted via telephone interviews and the second follow-up via telephone interviews and postal questionnaires. During the two follow-up years 41 participants died and 15 were admitted to institutional care. Other reasons for attrition were inability to communicate (12), moving outside the study area (6), poor health (5), not willing (6), and not reached (2). The present analyses utilize data on 824 older people who had answered the question on personal goals at baseline. Of these, 795 participated in the one-year and 742 in the two-year follow-up.

This study was approved by the ethical committee of the University of Jyväskylä, Finland, and the participants gave their written informed consent. Good scientific practice was followed throughout the study in accordance with the principles laid down by the Declaration of Helsinki.

Measurements

Life-space mobility. Life-space mobility was measured using the University of Alabama at Birmingham Study of Aging Life-Space Assessment [2] in face-to-face interviews at baseline and in telephone interviews at the first and second follow-ups. The Life-Space Assessment 
was translated into Finnish [20]. A test-retest study found the measurement to be fairly reliable and responsive to change in the Finnish context regardless of season [21]. The assessment includes six nested life-space tiers starting from the bedroom and expanding to include home, yard, neighborhood, town, and beyond town. The participants were asked how often they moved in these different life-space tiers and whether they needed help from any devices or another person to do so. For the analysis we used the life-space mobility composite score (LSMC score), which reflects the distance, frequency, and level of independence of mobility. The score ranges from 0 to 120 with higher scores indicating higher life-space mobility.

Personal goals. The content of personal goals was asked with a revised version of Brian R. Little’s [22] Personal Project Analysis. The following instruction was used in the interview: "We all have different personal goals that we strive to realize in our daily lives or reach in the future. The goals may be related to any life domain, such as hobbies, daily life, health, family, or friends. Think about the goals you have at the moment. The goals can be big or small; the main thing is that they are important for you.” The participants reported between zero and seven personal goals. A coding scheme with 25 goal categories was designed for the purpose of classifying goal content, utilizing the coding scheme developed by Salmela-Aro et al. [23]. The goals were classified independently by two trained assessors, and the percentage rate of agreement between the assessors was 89\%. Discrepancies between the assessors were discussed until total agreement was achieved. Each of the 25 personal goal categories was coded on a dichotomous scale, 1 indicating having at least one goal in the category, and 0 no goals in the category. A person could have goals in several different categories or several goals in one category. We added a separate category of "no goals", in which 1 indicated having no goals and 0 at least one goal in any of the 25 goal categories. The goal categories and examples of their content are presented in Table 1.

Covariates. Participants' date of birth was derived from the national population register, while the data for all the other covariates were collected during home interview. The other covariates were years of education, perceived economic situation (good or very good vs. moderate, poor, very poor), and perceived difficulties in walking two kilometers (no difficulties, minor difficulties and major difficulties / unable). Number of chronic diseases was calculated based on physician-diagnosed conditions, self-reported from a list of 22 chronic conditions, including e.g., coronary artery disease, arthritis, diabetes, cancer, Parkinson's disease, Alzheimer's disease or other dementia, depression, visual impairment, 
and hearing loss. Diagnoses not included in the list were prompted with an additional open question [8].

Statistical analysis

The descriptive characteristics of the participants are reported as mean values and standard deviations for continuous variables and percentage distributions for categorical variables. Independent sample's t-test and chi-square test were used to compare differences in the descriptive characteristics between those who did versus those who did not report at least one personal goal. The correlations between the study variables were computed using Spearman's rank correlation coefficient.

To study the changes in the LSMC score based on reporting vs. not reporting personal goals in each goal category, we conducted a generalized estimating equations (GEE) model [24] by specifying an unstructured outcome covariance matrix. This feature is an advantage in comparison with models that are based on the assumption of compound symmetry (i.e., constant covariance) of the outcome covariance matrix (e.g., repeated measures variance analysis). We estimated main effects of personal goals on life-space mobility and timeinteraction effects for the one- and two-year follow-ups. Due to the large number of goal categories, we only included in the analysis goal categories for which a significant difference $(\mathrm{p}<.10)$ was observed in the LSMC score at baseline or at either of the follow-ups. Also, categories in which fewer than 30 participants reported having goals were not analyzed further as lack of power prevented meaningful multivariate modelling. This resulted in 11 goal categories for inclusion in the GEE -model. As the correlations between the goal categories were low (range from -.131 to .194), indicating no substantial collinearity, we were able to include all of them in the same model as individual dummy predictor variables. We conducted an age and sex-adjusted model, and a model which was further adjusted for years of education, perceived economic situation, number of chronic conditions, and perceived difficulties in walking two kilometers (fully adjusted). There were no substantial differences between the models, and thus we report only the results of the fully adjusted model. A separate GEE -model with similar adjustments, in which at least one goal reported was as a predictor variable, was used to study changes in the LSMC score. The level of statistical significance was set at $\mathrm{p}<.05$. The analyses were conducted using SPSS 20.0 for Windows (IBM SPSS Inc.). 


\section{Results}

Descriptive results

The average age of the participants was 80.6 ( $\mathrm{SD} \pm 4.2$ ), $62 \%$ of them were women, and $41 \%$ reported having at least minor difficulties in walking two kilometers. The average LSMC score was $64.3( \pm 20.5)$ at baseline, $62.6( \pm 22.0)$ at the first follow-up, and $61.7( \pm$ 21.9) at the second follow-up. The participants reported between zero and seven personal goals. Those who did not report any goals were older, had somewhat less education, more often reported having difficulties in walking two kilometers, and had a lower LSMC score compared to those reporting at least one personal goal (Table 2).

Personal goals related to maintaining health (32\% had at least one goal in this category) and maintaining functioning (20\%) were the most frequently reported by the participants. The LSMC score at baseline was significantly higher among those reporting goals related to maintaining functioning, activeness in daily life, exercise, hobbies at home, meeting other people, mental health, or travel/summer cottage when compared to those not reporting such goals. Those with goals related to recovery/managing illnesses or to improving functioning had significantly lower LSMC score compared to those not reporting such goals (Table 1).

The associations of personal goals with life-space mobility

The GEE -model showed that those who did not report any personal goals had a somewhat lower LSMC score than those who reported at least one personal goal in any of the goal categories (marginal mean \pm SD: $61 \pm 2.6$ vs. $65 \pm 0.6$; $\mathrm{p}=.06$ ). This difference persisted throughout the two follow-up years ( $59 \pm 2.6$ vs. $63 \pm 0.6$ at the first follow-up and $57 \pm 2.5$ vs. $61 \pm 0.6$ at the second follow-up; group $\mathrm{x}$ time interaction effect $\mathrm{p}=.994$; fully adjusted model).

The time effect on the fully adjusted GEE -model with 11 goal categories as separate predictor variables was not significant $(\mathrm{p}=0.981)$. Participants who reported goals related to maintaining functioning had a relatively stable LSMC score, whereas the scores of those with no such goals decreased over the years. Those with goals related to activeness in daily life, exercise, and mental health had a higher LSMC score at baseline compared to those with no such goals. The differences between the groups persisted over the two-year follow-up for 
goals related to exercise and mental health, and over the one-year follow-up for goals related to activeness in daily life. Those who reported goals related to improving functioning had a lower LSMC score at baseline than those with no such goals, and the difference between the groups remained over both follow-up years (Table 3).

\section{Discussion}

Personal goals indicating a desire to be active in daily life, to exercise, and to stay mentally alert were associated with higher life-space mobility and the associations persisted in the longitudinal analysis. At baseline, goals related to maintaining functioning were not associated with the LSMC score, but were predictive of maintaining higher life-space mobility when compared to those not reporting such goals, among whom the LSMC score decreased over the following two years. In turn, goals reflecting improvement in physical functioning were associated with a lower LSMC score at the two-year follow-up. Also, reporting at least one personal goal in any of the goal categories was associated with a higher LSMC score over the follow-up years. Since higher life-space mobility correlates with better quality of life [9] and decreased risk for frailty and mortality [11], our results indicate that striving for both physical and mental activity may even increase well-being in old age.

Life-space mobility is strongly associated with functional ability [6, 8], but it also reflects interest in moving around and participating in social networks [4]. As goals may indicate an orientation toward the future, the current results are in line with those of a previous study indicating that older people who orient more to the future have larger lifespace than those who focus mostly on the present day [4]. Endorsing goals in life may also signify willingness, and the ability, to plan the future, which has also been associated with larger life-space [7]. Several goal categories predicted higher life-space mobility, even when the analysis was adjusted for e.g., health conditions and functional limitations. This strengthens the notion that in addition to physical functioning, psycho-social factors also contribute to life-space mobility. Similar finding was reported by Portegijs et al. [8] who concluded that alongside physical performance, sense of autonomy is also associated with life-space mobility.

The finding that reporting personal goals related to activeness in daily life and to exercise were associated with higher life-space mobility may be explained by the notion that those who endorse such goals are also more physically active [17], and thus in a better physical condition and able to move within a larger life-space. Personal goals are reflective of 
older people's health and functional abilities $[14,15]$. It is possible that the people with activity-related goals were initially healthier, and thus able to better maintain their higher lifespace mobility over the years. However, the associations between activity-related goals and life-space mobility were not attenuated even when the analysis was adjusted for indicators of health and functioning. Some of the goals related to activeness in daily life did not require travelling far from home (e.g., gardening), and as such do not explain the correlation with higher life-space mobility. However, these goals may reflect a tendency to be generally active in life, potentially manifested as higher life-space mobility. The same tendency may explain the result that goals related to mental health predicted higher life-space mobility. In our data these goals often reflected strivings to stay mentally alert, and thus may relate to higher activity participation, in turn reflected in higher life-space mobility. Also, goals related to maintaining functioning may indicate strivings to stay active and take care of one's health and functional ability. This was not reflected in life-space mobility immediately, but did predict a higher LSMC score over time. The associations of different activity-related goals with life-space mobility suggest that although goal disengagement is common in old age [15], persistence in the pursuit of active life goals might be more beneficial for older people's physical well-being. Maintaining activity despite age-related functional decline may even decrease mortality risk [25].

Goals related to improving functioning were associated with lower life-space mobility, and the difference in the LSMC score between those who reported these goals versus those who did not, remained the same over the two-year follow-up. In our data, these goals were often reported by people with poorer health and functioning, and thus typically indicated a desire to regain an earlier state of functional ability. As life-space mobility is strongly associated with physical functioning, it is understandable that these goals relate to lower life-space mobility. However, as goals related to improving functioning did not predict a higher LSMC score in the two-year follow-up, they may stem from ruminating over one's own situation instead of active striving toward improved functioning. As goals render life meaningful [26], it would be important to encourage older people with functional problems to strive for, e.g., recreational goals in their lives. Such goals might motivate them to extend their life-space, which, in turn, might promote their functional ability.

This study is the first to examine the relations between personal goals and life-space mobility among older people. Moreover, by utilizing a longitudinal study design, we were able to demonstrate that some personal goals may predict changes in life-space mobility in old age. Due to the low correlation between the goal categories, we were able to include all of 
them in the same GEE -model. This allowed us to identify which specific goals were the most significant predictors of changes in life-space mobility. Also, we were able to adjust our models for indicators of health and functioning, strengthening the assumption that goals may motivate older people to maintain a larger life-space irrespective of their physical condition. The participants represented both sexes and a wide age range of community-dwelling older people, which adds to the generalizability of the study.

There are also some limitations that need to be considered when interpreting the results of this study. The participants were somewhat healthier than average for their age. Moreover, people with severe communication problems, most likely due to cognitive impairment, were excluded from the study. The associations found might have been stronger had the participants shown more variation in physical and cognitive functioning. While we conclude that goals may be relevant for older people's life-space mobility, we also recognize that the ability to move around one's neighborhood and beyond and the level of independence one has in travelling contribute to older people's possibilities to set personal goals. In the personal project analysis, the participants reported their goals without using a structured questionnaire. Thus the participants might have had additional goals that they did not report in the interview. We have no data on the participants' goals at the follow-up and thus cannot know if or how they changed, or how any such changes might have been reflected in lifespace mobility longitudinally. Also, we cannot know to what degree the participants acted according to their personal goals.

\section{Conclusion}

Striving for personal goals may encourage older people to leave their home and move within a wider life-space. This may have important health benefits, as leaving the home is the single most important factor for increasing physical activity among older people [27]. In particular, goals related to being active, exercising, and maintaining functioning may benefit the quality of life of older people by enabling them to maintain a wider life-space $[9,10]$. On the contrary, lack of interest in moving outside the home may result in some older people spending time mainly at home [4], inevitably leading to sedentary behavior [27].

Consequently, supporting older people in striving for meaningful goals in their lives might contribute to a larger life-space and improved quality of life in old age. 
Acknowledgments: We thank Michael Freeman for revising the English language of the manuscript.

Funding: This work was supported by the University of Jyväskylä, the Academy of Finland (the Future of Living and Housing; Grant 255403 for the LISPE project), and the Finnish Ministry of Education and Culture.

Conflict of interest statement: The authors declare that there are no conflicts of interest.

\section{References}

1. Satariano WA, Guralnik JM, Jackson RJ, Marottoli RA, Phelan EA, Prohaska TR (2012) Mobility and Aging: new directions for public health action. Am J Public Health 102:1508-1515. doi:10.2105/AJPH.2011.300631

2. Baker PS, Bodner EV, Allman RM (2003) Measuring life-space mobility in communitydwelling older adults. J Am Geriatr Soc 51:1610-1614. doi:10.1046/j.15325415.2003.51512.x

3. Allman RM, Sawyer P, Roseman JM (2006) The UAB study of aging: background and insights into life-space mobility among older Americans in rural and urban settings. Aging Health 2:417-429. doi:10.2217/1745509X.2.3.417

4. Barnes LL, Wilson RS, Bienias JL, Mendes de Leon CF, Kim H-JN, Buchman AS, Bennett DA (2007) Correlates of life space in a volunteer cohort of older adults. Exp Aging Res 33:77-93. doi:10.1080/03610730601006420

5. Al Snih S, Peek, KM, Sawyer P, Markides KS, Allman RM, Ottenbacher KJ (2012) Lifespace mobility in Mexican Americans aged 75 and older. J Am Geriatr Soc 60:532-537. doi:10.1111/j.1532-5415.2011.03822.x

6. Peel C, Baker PS, Roth DL, Brown CJ, Bodner EV, Allman RM (2005) Assessing mobility in older adults: the UAB Study of Aging Life-Space Assessment. Phys Ther 85:10081019.

7. Sartori AC, Wadley VG, Clay OJ, Parisi JM, Rebok GW, Crowe M (2012) The relationship between cognitive function and life-space: the potential role of personal control beliefs. Psychol Aging 27:364-374. doi: 10.1013/a0025212

8. Portegijs E, Rantakokko M, Mikkola TM, Viljanen A, Rantanen T (2014) Association between physical performance and sense of autonomy in outdoor activities and life-space mobility in community-dwelling older people. J Am Geriatr Soc 62:615-621. doi: 10.1111/jgs.12763. 
9. Rantakokko M, Portegijs E, Viljanen A, Iwarsson S, Rantanen T (2013) Life-space mobility and quality of life in community-dwelling older people. J Am Geriatr Soc 61:1830-1832. doi:10.1111/jgs.12473

10. Rantakokko M, Portegijs E, Viljanen A, Iwarsson S, Rantanen T. Changes in life-space mobility and quality of life among community-dwelling older people: a two-year followup study. Manuscript submitted.

11. Xue Q-L, Fried LP, Glass TA, Laffan A, Chaves PHM (2008) Life-space constriction, development of frailty, and the competing risk of mortality. The Women's Health and Aging Study I. Am J Epidemiol 167:240-248. doi:10.1093/aje/kwm270

12. Deci EL, Ryan RM. The "what” and "why” of goal pursuits: human needs and the selfdetermination of behavior. Psychol Inq 2000 11:227-268. doi:10.1207/S15327965PLI1104_01

13. Freund AM, Riediger M (2006) Goals as building blocks of personality and development in adulthood. In: Mroczek DK, Little TD (eds) Handbook of personality development. Laurence Erlbaum Associates, Mahwah, New Jersey, pp 353-372

14. Lawton MP, Moss MS, Winter L, Hoffmann C (2002) Motivation in later life: personal projects and well-being. Psychol Aging 17:539-547. doi:10.1037/0882-328 7974.17.4.539

15. Saajanaho M, Viljanen A, Read S, Eronen J, Kaprio J, Jylhä M, Rantanen T (2014) Mobility limitation and changes in personal goals among older women. J Gerontol B Psychol Sci Soc Sci. doi:10.1093/geronb/gbu094.

16. Holahan CK (1988) Relation of life goals at age 70 to activity participation and health and psychological well-being among Terman's gifted men and women. Psychol Aging 3:286-291. doi:10.1037//0882-7974.3.3.286

17. Saajanaho M, Viljanen A, Read S, Rantakokko M, Tsai L-T, Kaprio J, Jylhä M, Rantanen $\mathrm{T}$ (2014) Older women's personal goals and exercise activity: an 8-year follow-up. J Aging Phys Act 22:386-392. doi:10.1123/JAPA.2012-0339

18. Haase CM, Heckhausen J, Wrosch C (2013) Developmental regulation across the life span: towards a new synthesis. Dev Psychol 49:964-972. doi:10.1037/a0029231

19. Baltes PB (1997). On the incomplete architecture of human ontogeny. Selection, optimization, and compensation as foundation of developmental theory. Am Psychol 52, 366-380.

20. Rantanen T, Portegijs E, Viljanen A, Eronen J, Saajanaho M, Tsai L-T, Kauppinen M, Palonen E-M, Sipilä S, Iwarsson S, Rantakokko M (2012) Individual and environmental factors underlying life space of older people - study protocol and design of a cohort study 
on life-space mobility in old age (LISPE). BMC Public Health 12:1018. doi: $10.1186 / 1471-2458-12-1018$

21. Portegijs E, Iwarsson S, Rantakokko M, Viljanen A, Rantanen, T (2014) Life-space mobility assessment in older people in Finland; measurement properties in winter and spring. BMC Research Notes 7:323. doi:10.1186/1756-0500-7-323

22. Little BR (1983) Personal projects. A rationale and method for investigation. Environ Behav 15:273-309. doi:10.1177/0013916583153002

23. Salmela-Aro K, Read S, Nurmi J-E, Koskenvuo M, Kaprio J, Rantanen T (2009). Personal goals of older female twins. Genetic and environmental effects. Eur Psychol 14:160-167. doi:10.1027/1016-9040.14.2.160

24. Liang KY, Zeger S (2006). Longitudinal data analysis using generalized linear models. Biometrika 73:13-22. doi:10.2307/2336267

25. Hirvensalo M, Rantanen T, Heikkinen E (2000) Mobility difficulties and physical activity as predictors of mortality and loss of independence in the community-living older population. J Am Geriatr Soc 48:493-498

26. Betzler M (2013) The normative significance of personal projects. In Kühler M, Jelinek N (eds) Autonomy and the Self. Philosophical Studies Series 118. Springer Science + Business Media, Dordrecht, Germany, pp 101-126

27. Tsai L-T, Portegijs E, Rantakokko M, Viljanen A, Saajanaho M, Eronen J, Rantanen T (2015) The association between objectively measured physical activity and life-space mobility among older people. Scand J Med Sci Spor. doi:10.1111/sms.12337 
Table 1. The personal goal categories, examples of their content, number of participants reporting them, and average life-space mobility score at baseline by reporting vs. not reporting goals in each goal category $(n=824$, LISPE study conducted in Central Finland in 2012-2014)

\begin{tabular}{|c|c|c|c|c|c|}
\hline \multirow[b]{3}{*}{ Personal goal category } & \multirow[b]{3}{*}{ Example } & \multirow[b]{3}{*}{$\begin{array}{l}\%(n) \\
\text { reporting }\end{array}$} & \multicolumn{3}{|c|}{ Life-space mobility score } \\
\hline & & & \multicolumn{2}{|c|}{ Goal } & \multirow[b]{2}{*}{$\begin{array}{c}\text { p- } \\
\text { value* }^{*}\end{array}$} \\
\hline & & & $\begin{array}{c}\text { Yes } \\
(\text { mean } \pm \text { SD) }\end{array}$ & $\begin{array}{c}\text { No } \\
(\text { mean } \pm \text { SD) }\end{array}$ & \\
\hline Maintaining health & “To stay healthy” & $32(263)$ & $66 \pm 19.8$ & $64 \pm 20.7$ & .165 \\
\hline Maintaining functioning & “To maintain functional ability" & $20(165)$ & $68 \pm 18.6$ & $63 \pm 20.8$ & .009 \\
\hline Activeness in daily life & “Going outside everyday" & $16(133)$ & $69 \pm 19.4$ & $63 \pm 20.5$ & .002 \\
\hline Travel / summer cottage & “To travel to some place warm" & $15(124)$ & $68 \pm 17.3$ & $64 \pm 20.9$ & .006 \\
\hline Family & "To visit children" & 14 (119) & $63 \pm 21.1$ & $64 \pm 20.4$ & .580 \\
\hline Independent living & $\begin{array}{l}\text { "To be able to take care of myself } \\
\text { and my home" }\end{array}$ & $15(124)$ & $62 \pm 22.0$ & $65 \pm 20.2$ & .187 \\
\hline Hobbies at home & “To do handicrafts" & $14(111)$ & $69 \pm 19.3$ & $63 \pm 20.5$ & .004 \\
\hline Exercise & “To exercise more” & $10(85)$ & $72 \pm 17.2$ & $63 \pm 20.6$ & $<.001$ \\
\hline Meeting other people & “Spending time with friends" & $13(107)$ & $69 \pm 18.7$ & $64 \pm 20.7$ & .012 \\
\hline Life as it is & "That life would stay as it is" & $9(76)$ & $64 \pm 21.9$ & $64 \pm 20.2$ & .920 \\
\hline Healthy lifestyle & "Living healthy" & $8(68)$ & $65 \pm 19.2$ & $64 \pm 20.6$ & .792 \\
\hline Participation in social events & $\begin{array}{l}\text { “To participate in war veterans’ } \\
\text { events” }\end{array}$ & $6(48)$ & $69 \pm 19.3$ & $64 \pm 20.5$ & .087 \\
\hline Helping others & $\begin{array}{l}\text { “To support children in their } \\
\text { lives” }\end{array}$ & $6(48)$ & $69 \pm 19.3$ & $64 \pm 20.5$ & .073 \\
\hline Other's health and well-being & $\begin{array}{l}\text { "Good future for our } \\
\text { grandchildren" }\end{array}$ & $6(45)$ & $69 \pm 19.2$ & $64 \pm 20.5$ & .131 \\
\hline Mental health & “To stay mentally alert” & $5(38)$ & $75 \pm 14.9$ & $64 \pm 20.6$ & $<.001$ \\
\hline Recovery / Managing illnesses & $\begin{array}{l}\text { "That cancer treatment would } \\
\text { work" }\end{array}$ & $5(38)$ & $56 \pm 20.8$ & $65 \pm 20.4$ & .008 \\
\hline Improving functioning & $\begin{array}{l}\text { "To be able to walk normally, as } \\
\text { before" }\end{array}$ & $4(34)$ & $54 \pm 21.9$ & $65 \pm 20.3$ & .004 \\
\hline Hobbies outside home & "Continue going to concerts" & $4(33)$ & $66 \pm 20.1$ & $64 \pm 20.5$ & .546 \\
\hline Economic issues & “To save money" & $4(32)$ & $68 \pm 26.5$ & $64 \pm 20.2$ & .239 \\
\hline Living arrangements & "To move to the city center" & $4(32)$ & $64 \pm 19.4$ & $64 \pm 20.5$ & .955 \\
\hline Character & $\begin{array}{l}\text { "To be as good a person as } \\
\text { possible" }\end{array}$ & $2(20)$ & $64 \pm 17.9$ & $64 \pm 20.5$ & .976 \\
\hline End-of-life issues & $\begin{array}{l}\text { "I have lost all interest in life, I'm } \\
\text { waiting for death" }\end{array}$ & $2(13)$ & $54 \pm 21.0$ & $64 \pm 20.4$ & .081 \\
\hline Common good & $\begin{array}{l}\text { "To participate in the } \\
\text { development of society" }\end{array}$ & $2(14)$ & $66 \pm 22.0$ & $64 \pm 20.5$ & .782 \\
\hline Philosophy of life / religion & "To live according to God's will” & $2(12)$ & $56 \pm 28.1$ & $64 \pm 20.3$ & .178 \\
\hline Other & "To have a dog" & $1(11)$ & $65 \pm 12.8$ & $64 \pm 20.6$ & .803 \\
\hline No goals & "I have no goals anymore" & $6(51)$ & $56 \pm 21.1$ & $65 \pm 20.3$ & .002 \\
\hline
\end{tabular}

* Independent samples t-test 
Table 2. Descriptive characteristics of the total study population and by reporting vs. not reporting any personal goals ( $n=824$, LISPE study conducted in Central Finland in 20122014)

\begin{tabular}{lcccc}
\hline & & \multicolumn{2}{c}{$\begin{array}{c}\text { Endorsing at least one } \\
\text { personal goal }\end{array}$} \\
\cline { 3 - 4 } & All & $\begin{array}{c}\text { Yes } \\
(\mathrm{n}=773)\end{array}$ & $\begin{array}{c}\text { No } \\
(\mathrm{n}=51)\end{array}$ & \\
& & & & $\mathrm{p}^{-}$ \\
& $\mathrm{M}(\mathrm{SD})$ & $\mathrm{M}(\mathrm{SD})$ & $\mathrm{M}(\mathrm{SD})$ & value* $^{*}$ \\
\hline Age in years & $80.6 \pm 4.2$ & $80.4 \pm 4.2$ & $82.4 \pm 4.1$ & .001 \\
Years of education & $9.6 \pm 4.2$ & $9.7 \pm 4.2$ & $8.6 \pm 4.1$ & .066 \\
Number of chronic conditions & $4.4 \pm 2.4$ & $4.4 \pm 2.5$ & $4.2 \pm 2.2$ & .711 \\
Life-space mobility score & $64.3 \pm 20.5$ & $64.8 \pm 20.3$ & $55.8 \pm 21.1$ & .005 \\
& $\%$ & $\%$ & $\%$ & \\
Women & 62 & 63 & 57 & .412 \\
Good economic situation & 51 & 51 & 51 & .971 \\
Difficulties in walking 2 km & & & & .065 \\
$\quad$ No difficulties & 59 & 60 & 43 & \\
Minor difficulties & 20 & 20 & 29 & \\
$\quad$ Major difficulties / unable & 21 & 21 & 28 & \\
\hline
\end{tabular}

* independent samples t-test for continuous variables and chi-square test for categorized variables; significance level $\mathrm{p}<.005$

Note: Years of education $n=817$; Economic situation $n=822$ 
Table 3. Goal categories jointly predicting changes in life-space mobility score in a GEE model (LISPE study conducted in Central Finland in 2012-2014, 824 participants)

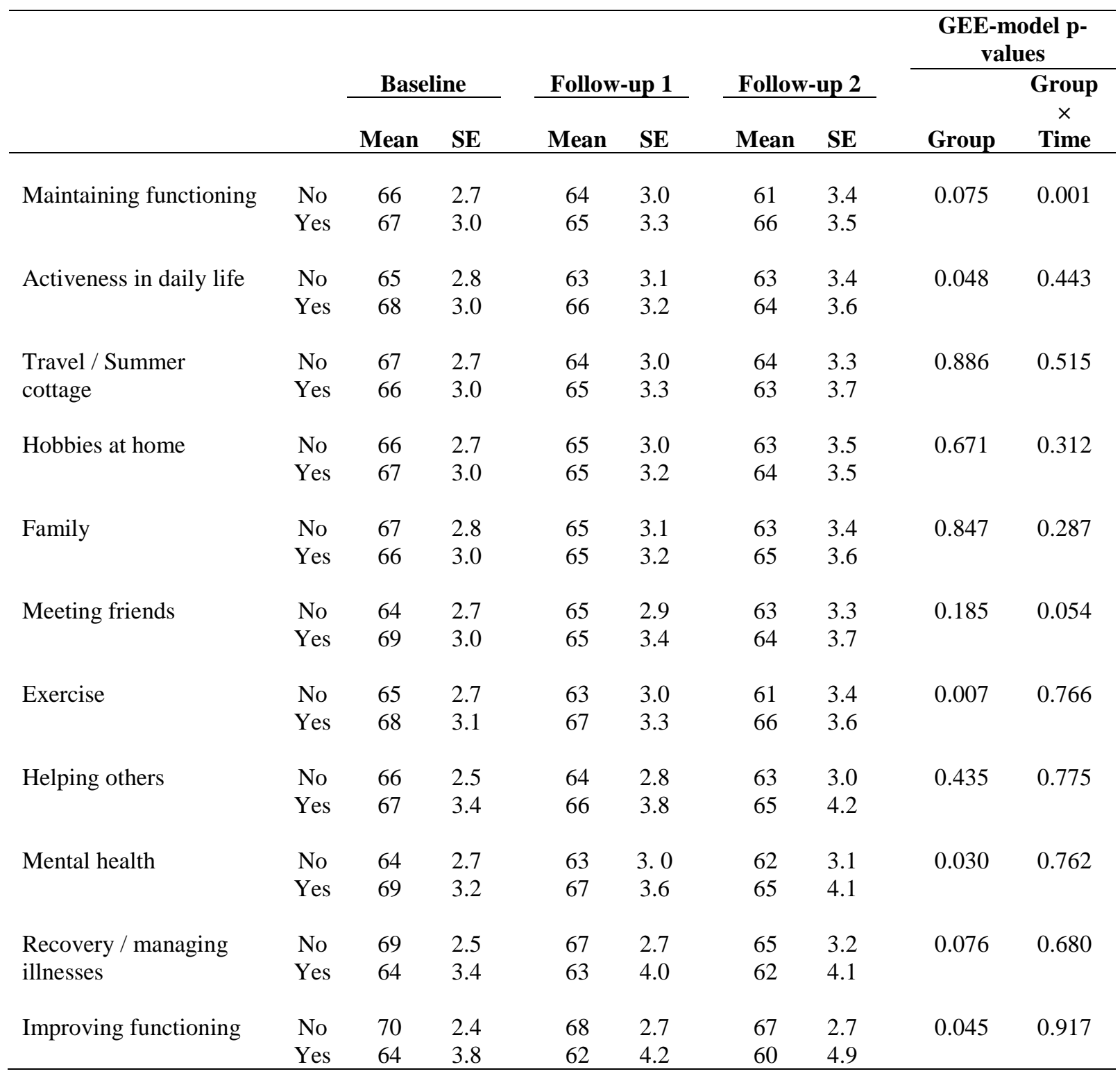

Note. GEE-model; adjusted for age, sex, years of education, economic situation, number of chronic conditions and difficulties in walking two kilometers; Mean=marginal mean, $\mathrm{SE}=$ Standard error of marginal mean 